\title{
Enhanced Gene Delivery in Bacterial and Mammalian Cells Using PEGylated Calcium Doped Magnetic Nanograin
}

This article was published in the following Dove Press journal: International Journal of Nanomedicine

\author{
Ehsan Hashemi ${ }^{1,2}$ \\ Hossein Mahdavi ${ }^{3}$ \\ Jafar Khezri' \\ Farideh Razi ${ }^{2,4}$ \\ Mehdi Shamsara' \\ Abbas Farmany (iD $)^{5}$ \\ 'National Research Center for \\ Transgenic Mouse \& Animal \\ Biotechnology Division, National \\ Institute of Genetic Engineering and \\ Biotechnology, Tehran, Iran; \\ ${ }^{2}$ Endocrinology and Metabolism Research \\ Center, Endocrinology and Metabolism \\ Clinical Sciences Institute, Tehran \\ University of Medical Sciences, Tehran, \\ Iran; ${ }^{3}$ School of Chemistry, College of \\ Science, University of Tehran, Tehran, \\ Iran; ${ }^{4}$ Diabetes Research Center, \\ Endocrinology and Metabolism Clinical \\ Sciences Institute, Tehran University of \\ Medical Sciences, Tehran, Iran; ${ }^{5}$ Dental \\ Implant Research Center, Hamadan \\ University of Medical Sciences, Hamadan, \\ Iran
}

Correspondence: Abbas Farmany Dental Implant Research Center, Hamadan University of Medical Sciences, Hamadan, Iran

Email a.farmany@ut.ac.ir
Background: Beyond viral carriers which have been widely used in gene delivery, non-viral carriers can further improve the delivery process. However, the high cytotoxicity and low efficiency impedes the clinical application of non-viral systems. Therefore, in this work, we fabricated polyethylene glycol (PEG) coated, calcium doped magnetic nanograin $\left(\mathrm{PEG} / \mathrm{Ca}(\mathrm{II}) / \mathrm{Fe}_{3} \mathrm{O}_{4}\right)$ as a genome expression enhancer.

Methods: Monodisperse magnetic nanograins (MNGs) with tunable size were synthesized by a solvothermal method. The citrate anions on the spherical surface of MNGs capture $\mathrm{Ca}^{2+}$ ions by an ion exchange process, which was followed by surface capping with PEG. The synthesized PEG/Ca(II)/ $\mathrm{Fe}_{3} \mathrm{O}_{4}$ was characterized using Fourier-transform infrared spectroscopy (FTIR), dynamic light scattering (DLS) spectra, vibrating sample magnetometer (VSM), transmission electron microscopy (TEM), and scanning electron microscopy (SEM). MTT test was utilized to assess the toxicity of PEG/Ca(II)/ $\mathrm{Fe}_{3} \mathrm{O}_{4}$. Real time qPCR was applied for quantification of gene expression.

Results: DLS spectra and TEM images confirmed a thin layer of PEG on the nanocarrier surface. Shifting the zeta potential in the biological $\mathrm{pH}$ window from $-23.9 \mathrm{mV}$ (for $\mathrm{Fe}_{3} \mathrm{O}_{4}$ ) to $\approx+11 \mathrm{mV}$ (for $\mathrm{PEG} / \mathrm{Ca}(\mathrm{II}) / \mathrm{Fe}_{3} \mathrm{O}_{4}$ ) confirms the MNGs surface protonation. Cytotoxicity results show that cell viability and proliferation were not hindered in a wide range of nanocarrier concentrations and different incubation times.

Conclusion: PEGylated calcium doped magnetic nanograin enhanced PUC19 plasmid expression into E. Coli and GFP protein expression in HEK-293 T cells compared to control. A polymerase chain reaction of the NeoR test shows that the transformed plasmids are of high quality.

Keywords: gene expression, calcium doped magnetic nanograins, cytotoxicity

\section{Introduction}

As a promising strategy, gene therapy has drawn significant attention, specially in cell therapy and treatment of gene-associated diseases ranging from hemophilia and cancer to autoimmune diseases. ${ }^{1,3}$ Clinical application of gene therapy depends on the efficiency and safety of its delivery vectors. Compared with the viral delivery vectors, nonviral vectors are relatively oncogenic, less immunogenic and easy to prepare, and specially have no limitation in the size of transferred genome material and no potential of virus recombination. ${ }^{4}$ At this time, many efforts have been attempted to fabricate the safe and efficiency gene vectors. There is intense activity in evaluating and developing non-viral carriers including polymers, ${ }^{5,6}$ cationic lipids, ${ }^{7}$ quantum dots, ${ }^{8,9}$ carbon 
nanotubes, ${ }^{10,11}$ graphene, ${ }^{12}$ silica nanoparticles, ${ }^{13,14}$ and gold nanoparticles ${ }^{15,8}$ with surface properties, tunable size, and multifunctional properties. The potential of large scale production and biocompatibility make non-viral carriers increasingly attractive. However, numerous intra- and extracellular obstacles significantly reduce their transfection efficiency.

Recently, superparamagnetic iron oxide nanoparticles have been widely explored for use in nanomedicine. Magnetic nanoparticles (MNPs) have been investigated in both therapeutic and diagnostic applications. ${ }^{19}$ The large surface area-to-volume ratio of MNPs renders these nanomaterials as a suitable candidate for drug and genome material loading and transport. ${ }^{20,25}$ Genome material may be attached to the particles employing target specific linkers or utilizing electrostatic interaction between positively charged polymers (PEI, etc. ...) attached to nanoparticle surface and negatively charged phosphate backbone of the genome material. $^{25}$

In the genome material, phosphate groups form ionic complexes with divalent metals such as $\mathrm{Ca}^{2+}, \mathrm{Ba}^{2+}$, and $\mathrm{Mg}^{2+}$ and stabilize the genome structure. ${ }^{26,30}$ As shown by Baoum et al, ${ }^{26,27}$ the $\mathrm{Ca}^{2+}$-lipoplex improves the transfection efficiency in accordance with a classical analog of gene delivery method in the presence of $\mathrm{Ca}^{2+}$. Also, Haberland et $\mathrm{al}^{28}$ reported that $\mathrm{Ca}^{2+}$ could enhance the gene transfer process. More recently, Chen et $\mathrm{al}^{29}$ showed that $\mathrm{Ca}^{2+}$ improved both packaging and release of plasmid DNA.As shown by Zaitsev et al, ${ }^{30}$ the cellular uptake is independent to $\mathrm{Ca}^{2+}$ in the absence and/or presence at the culture media. In fact, $\mathrm{Ca}^{2+}$ works to organize the transfection in the endosome/lysosome and its release into the cytosol. ${ }^{31,35}$

The aim of this study was to fabricate a highly biocompatible magnetic nanograin (MNG) for gene delivery. The nanocarrier is assembled from a citrate-stabilized magnetic nanograin core which spherically is doped by $\mathrm{Ca}^{2+}$ and surrounded by a polyethylene glycol (PEG) shell. The MNGs were applied in the PUC19 plasmid expression into E. coli and GFP protein expression in HEK-293 T cells as prokaryotic and eukaryotic cell models, respectively.

\section{Experimental Section}

Materials and Methods

Synthesis of MNGs

High quality monodisperse magnetic nanograins (MNGs) with tunable size were synthesized by a solvothermal method. $^{36}$ Following is a typical protocol for $\mathrm{MNG}$ synthesis (see Figure 1). $\mathrm{FeCl}_{3}(0.32 \mathrm{~g}, 4.0 \mathrm{mmol})$ and trisodium citrate $(0.10 \mathrm{~g}, 0.68 \mathrm{mmol})$ were first dissolved in ethylene glycol $(20 \mathrm{~mL})$, then $\mathrm{NaAc}(0.60 \mathrm{~g})$ was added with stirring. The mixture was stirred vigorously for 30 minutes and then sealed in a Teflon-lined stainless-steel autoclave. The autoclave was heated at $200^{\circ} \mathrm{C}$ and maintained for 10 hours, and then allowed to cool to room temperature. The synthesized MNGs were washed with ethanol and purified by precipitation with acetone. Stock solution of MNGs with concentration of $25 \mathrm{mg} / \mathrm{mL}$ was prepared by dispersing MNGs in ethanol.

\section{Synthesis of $\mathrm{Ca}$ (II) Doped MNGs}

In a typical synthesis, $10 \mathrm{mg}$ MNGs was first sonicated in ethanol and placed in a $25 \mathrm{~mL}$ round-bottom flask. The flask was purged with $\mathrm{N}_{2}$ for 5 minutes. Then $40 \mathrm{mg} \mathrm{CaCl}_{2}$ was dissolved in $5 \mathrm{~mL}$ ethanol and, after purging for 5 minutes with $\mathrm{N}_{2}$, it was swiftly injected to the MNGs. The mixture was stirred for 10 hours under $\mathrm{N}_{2}$. After a through washing with ethanol, to remove the excess salts, it was re-dispersed in $10 \mathrm{~mL}$ ethanol.

\section{PEGylation of $\mathrm{Ca}(\mathrm{II}) / \mathrm{MNGs}$}

Five millilters of aqueous solution $(2 \% \mathrm{w} / \mathrm{v})$ of PEG-2000 (MW) was swiftly injected into $\mathrm{Ca}(\mathrm{II}) / \mathrm{MNGs}$ under vigorous stirring with a stirring speed of $700 \mathrm{rpm}$. It was kept for 2 hours at room temperature. ${ }^{37}$ The resulting $\mathrm{PEG} / \mathrm{Ca}(\mathrm{II}) /$ MNGs were isolated by centrifugation, washed with ethanol, re-dispersed in ethanol, and stored at $4^{\circ} \mathrm{C}$ as stock solution.

\section{Instrumentation}

TEM measurements were taken on a Philip CM $120(120 \mathrm{kV})$. SEM measurements were made using a Scanning TESCAN (Vega). IR studies were run on a Spectrum 65 - PERKINELMER FTIR spectrophotometer. The hydrodynamic diameters of the nanoparticles were measured by a Microtrac Nanotrac Wave dynamic light scattering (DLS) instrument.

\section{Gene Expression Mechanism Study}

All the experiments were performed according to the following. ${ }^{38}$ First, PUC19 plasmid was added to the competent cells and divided into eight different groups: 1) The nanocarrier has been added immediately (optimal concentration of nanocarrier was $10 \mu \mathrm{g} / \mathrm{mL}$ ); 2) After 30 minutes the nanocarrier was added (before heat shock); 3) 30 seconds after starting heat shock the nanocarrier was added; 4) 60 seconds after starting heat shock the nanocarrier was added; 5) 90 seconds after starting heat shock the nanocarrier was added; 6) the nanocarrier was added after neutralizing with 
<smiles>O=C1CC2OPOOC(=O)CC(O)(C1)C2=O</smiles>

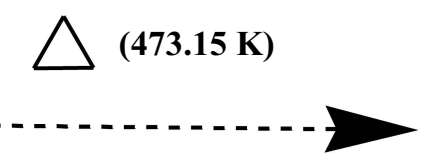

$10 \mathrm{~h}$

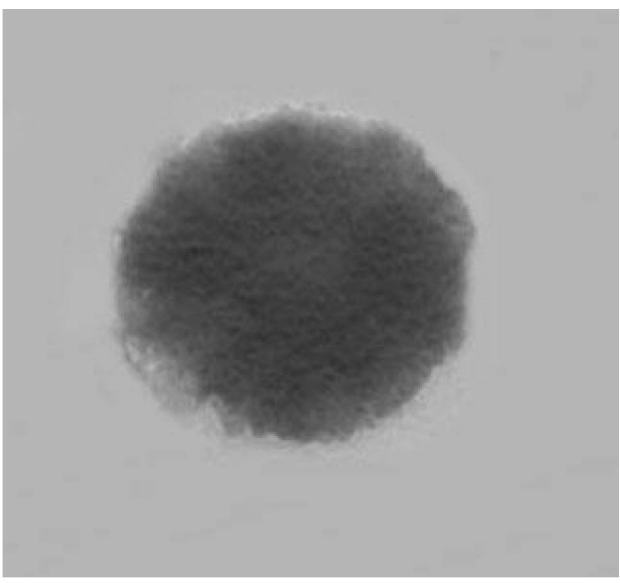

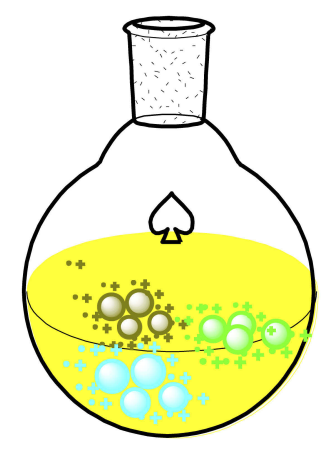

473.15 K, 10 h
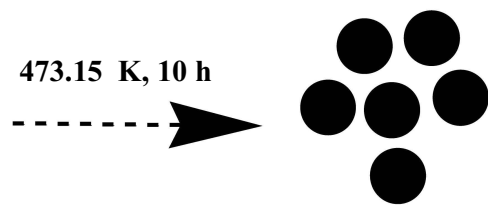
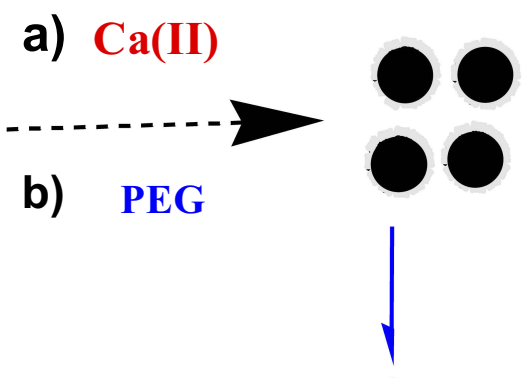

$\mathrm{Fe}($ IIII)

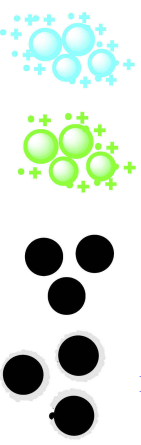

Sodium acetate

\section{3 sodium citrate}

Nanograins

PEG/Ca(II)/nanograins

Figure I Overall synthesis of monodisperse PEG/Ca(II)/MNGs.

LB media $(500 \mu \mathrm{L}) ; 7)$ the nanocarrier was added before transferring to culture plate; and 8) control group.

DNA Extraction, PCR, and Gel Electrophoresis pDNA molecules were extracted from E. coli bacteria. ${ }^{38}$ Extracted E. coli DNA was subjected to restriction enzyme digestion (RED) using MlsI (Ball) restriction enzyme (Fermentas, Cat. No.ER1211). To analyze the stability of extracted DNA, PCR was applied to the NeoR gene. Briefly, $1 \times$ PCR buffer ( $50 \mathrm{mM}$ Tris-HCl, $100 \mathrm{mM} \mathrm{NaCl}, \mathrm{pH} \sim 8.3$ ), $4 \mu \mathrm{L}$ isolated DNA sample, $4 \mathrm{mM} \mathrm{Mg}^{2+}, 50 \mu \mathrm{M}$ dNTPs, 6 IU Taq DNA polymerase and 10 pmol of each forward (5'GCAACATCAGGTCGGCCATTAC-3') and reverse (5'CTGGCAACAGGAAAGATGGAGC-3') primers. The
PCR reaction was performed by initial denaturation at $94^{\circ}$ $\mathrm{C}$ for 5 minutes, denaturation at $94^{\circ} \mathrm{C}$ for 30 seconds, and annealing at $60^{\circ} \mathrm{C}$ for 45 seconds in 35 cycles, and finally extension at $72^{\circ} \mathrm{C}$ for 45 seconds to obtain a $807 \mathrm{bp}$.

\section{Cell Culture and Viability Assay}

All cell lines used in this manuscript were commercially purchased from Pasteur Institute of Iran. MTT test was utilized to assess toxicity of nanocarrier in Hek293T cell lines. Cells were cultured in RPMI supplemented with $10 \%$ fetal bovine serum (FBS) and $50 \mathrm{IU} / \mathrm{mL}$ penicillin and $50 \mu \mathrm{g} / \mathrm{mL}$ streptomycin and incubated in a $5 \% \mathrm{CO}_{2}$ atmosphere at $37^{\circ} \mathrm{C}$.

Cultured cells in a 96-well plate exposed with different concentrations of nanocarrier $(0,0.1,1,10,100$, and 
$500 \mu \mathrm{g} / \mathrm{mL}$ ) and after 48 hours, viability of treated cells were tested by the MTT. The treated cells were incubated for 3 hours with MTT solution. Then, DMSO was added to the wells to solubilize formazan particles, and finally the absorbance was read at $580 \mathrm{~nm}$ using an ELISA reader (Microplate reader labsystem multiscan).

\section{In vitro Gene Delivery}

Hek293T cells were cultured in a 4-well tissue culture plate in a DMEM medium supplemented with $10 \%$ FBS in a $\mathrm{CO}_{2}$ incubator. To test the potential gene delivery of nanocarrier, the cultured cells were treated with nontoxic concentrations (obtained by MTT test) of nanocarrier (1 and $10 \mu \mathrm{g} / \mathrm{mL}$ ) and about $4 \mu \mathrm{g}$ of EGFP-contained pDNA (pEGFP-C1). A standard method (Lipofectamine2000) was utilized as control. After 8 hours of transfection, cells were washed and fresh media were added then, after 24 hours, the treated cells were monitored for detection of EGFP emission by a fluorescence inverted microscope (Nikon) at $490 \mathrm{~nm}$ excitation wavelengths.

\section{Gene Expression Analysis}

Total RNA was isolated from the treated and control cells by RNaeasy mini Kit (Qiagen, USA) manufacturer's protocol and kept at $-80^{\circ} \mathrm{C}$ until use. Then, a RevertAid First Strand cDNA Synthesis Kit (Thermo Fisher Scientific) was applied for cDNA synthesis. For quantification of gene expression, Real Time qPCR was applied. The final reaction volume reached 20 $\mu \mathrm{L}$ by mixing $8 \mu \mathrm{L}$ of $2 \times$ SYBR Green PCR Master Mix (Intron, Korea, 25344), $4 \mu \mathrm{L}$ of synthesized cDNA, and $0.5 \mu \mathrm{L}$ of each primer and deionized water. The ABI System (Applied Biosystems StepOne, USA) was used for Real-Time PCR under the following conditions: $95^{\circ} \mathrm{C}$ for 2 minutes, and 35 cycles of $95^{\circ} \mathrm{C}$ for 10 seconds and $60^{\circ} \mathrm{C}$ for 30 seconds.

\section{Statistical Analysis}

Experiments were assayed in triplicate and statistical analysis was performed with SPSS version 20.0 statistic software package. The student's $t$-test and analysis of variance (ANOVA) were used for analysis of the experimental data. A $P$-value of $<0.05$ was considered statistically significant.

\section{Results}

\section{Synthesis and Characterization of Magnetic Nanovector}

$\mathrm{PEG} / \mathrm{Ca}(\mathrm{II}) / \mathrm{MNGs}$ were prepared via thermal decomposition of iron chloride and trisodium citrate in the presence of sodium acetate in ethylene glycol. ${ }^{36,39}$ FT-IR spectra (Figure 2A) show the binding modes as 1,536 and $1,375 \mathrm{~cm}^{-1}$, which are related to symmetric and asymmetric stretches of carbonyl groups, whereas $550-590 \mathrm{~cm}^{-1}$ absorption shows the ligandnanoparticle binding. Furthermore, $1,050-1,220 \mathrm{~cm}^{-1}$ peaks may be assigned to the PEG functional groups. ${ }^{40,41,42}$ Notably, the peak near 711 and $875 \mathrm{~cm}^{-1}$ in PEG/Ca(II)/MNGs can be assigned to the vibration bands of $\mathrm{Ca}-\mathrm{O}$. As $\mathrm{Ca}$ is minor in the nanoparticle structure, its absorption peaks are not clear. ${ }^{43}$ Comparison between FT-IR spectra of naked MNGs and PEG capped MNGs show a little (blue) shift which implicates the surface changes of MNGs after PEG capping, where the new bands between $\mathrm{Fe}-\mathrm{O}$ and $\mathrm{O}-\mathrm{H}$ are formed. ${ }^{44}$ Zeta potential measurements at various $\mathrm{pH}$ were carried out to obtain the surface charge of nanocarrier. Figure 2B shows the zeta potential data of the MNGs and $\mathrm{PEG} / \mathrm{Ca}^{2+} / \mathrm{MNGs}$. As shown in Figure $2 \mathrm{~B}$, at physiological $\mathrm{pH}$, zeta potential was shifted from $-23.9 \mathrm{mV}$ to $+11.0 \mathrm{mV}$. This shift can be related to the less aggregation of PEGylated MNGs in aqueous solution compared to naked MNGs. In all cases, charge differences higher than $\pm 10 \mathrm{mV}$ show a greater inter-particle repulsion and, hence, increase the colloidal stability. ${ }^{45}$

Shifting the zeta potential to positive values confirms the protonation of MNGs surface which can be related to PEG capping of the $\mathrm{Ca}(\mathrm{II}) / \mathrm{MNG}$ surface. ${ }^{46}$ The magnetization hysteresis loop of nanocrystals was probed in a magnetic field up to $3 \mathrm{~T}$ at room temperature using a vibrating sample magnetometer (VSM). The results in Figure $2 \mathrm{C}$ show that the magnetic behavior of MNGs is similar to that of superparamagnetic materials. The saturation magnetization of MNGs at room temperature was 62.5 and $53.4 \mathrm{emu} / \mathrm{g}$ for MNGs and $\mathrm{PEG} / \mathrm{Ca}^{2+} / \mathrm{MNGs}$, respectively. The saturation magnetization of PEGylated crystals was decreased which may be attributed to the high weight fraction of PEG or a surfacerelated effect such as surface disorder. X-ray diffraction peaks $(2 \theta)$ at 30.0, 35.6, 43.8, 54.2, 57.2, and 62.5 (shown in Figure 2D) indexed to (220), (311), (400), (422), (511), and (440), which show the cubic spinel structure of MNGs.

Scanning electron microscopy (SEM) images showed the formation of spherical magnetic nanoparticles (Figure 3). Transmission electron microscopy (TEM) analysis revealed that magnetic nanoparticles were uniform and separated from one another and had an average diameter of $170 \mathrm{~nm}$ (Figure 3). Uniformity of nanoparticles was clearly demonstrated by TEM image of the colloidal packing. Spherically monodisperse images of MNGs speculate that the formation of this magnetic nanocarrier is probably driven by enhanced forces which originated from complex formation between 
A
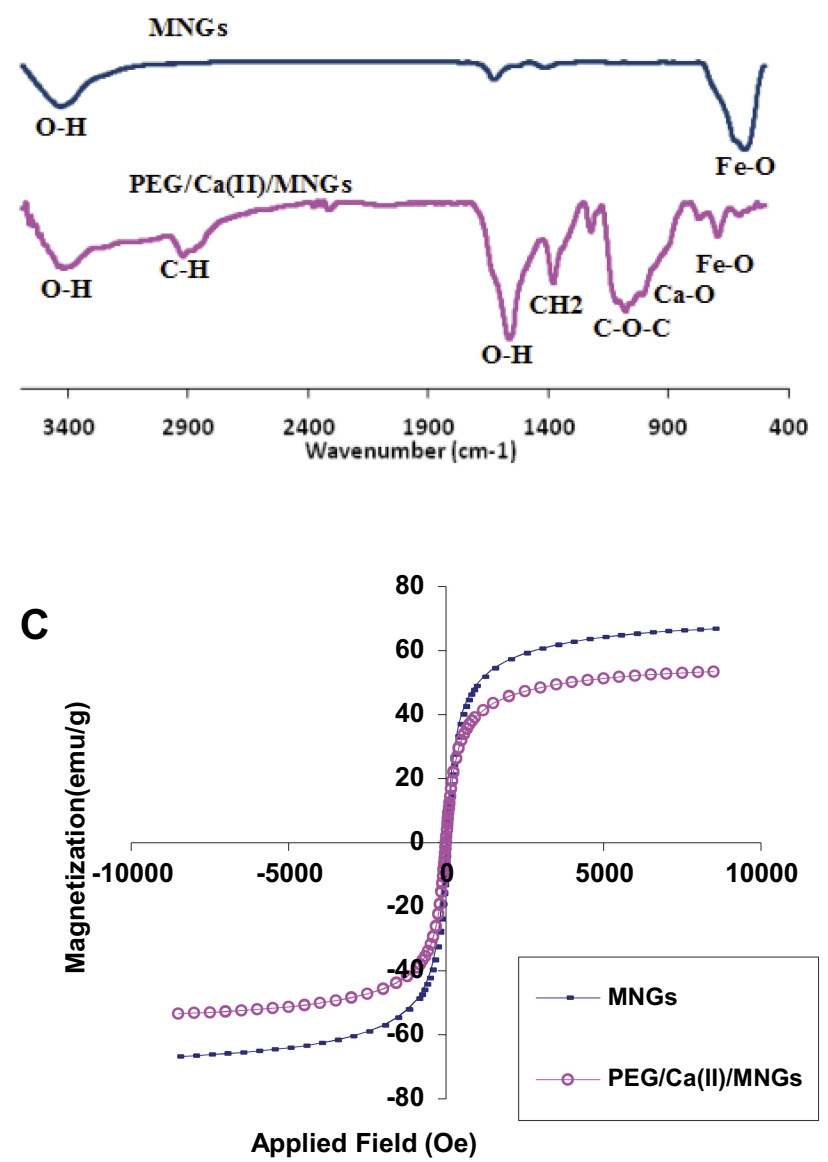
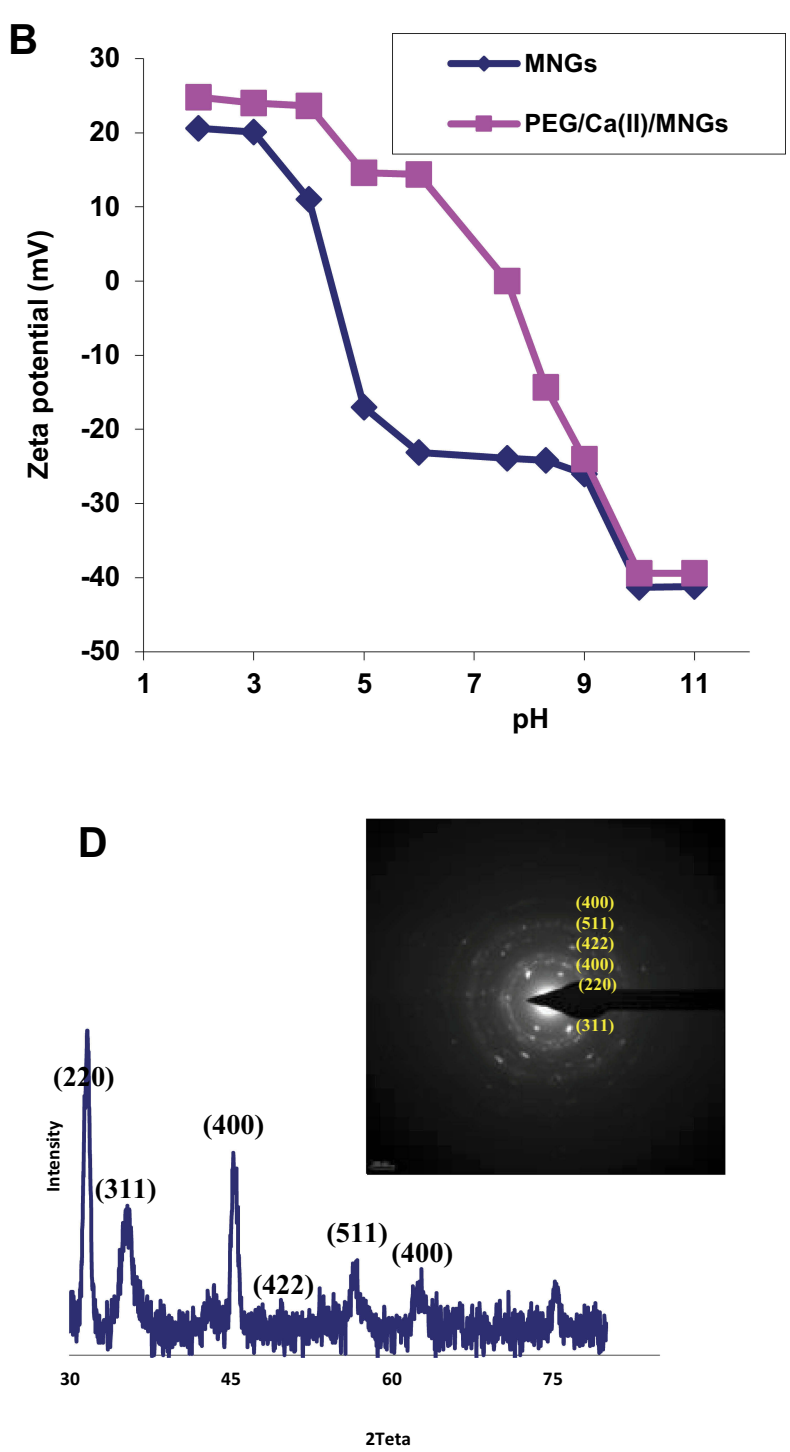

Figure 2 (A) FT-IR spectra of MNGs and PEG/Ca(II)/MNGs. (B) Zeta potential of MNGs and PEG/Ca(II)/MNGs. (C) Hysteresis loops of MNGs and PEG/Ca(II)/MNGs. In the inset: photograph of an aqueous PEG/Ca(II)/MNGs in a vial without/with magnetic field. (D) XRD pattern of bare MNGs. In the inset: SAED pattern of MNGs.

tricarboxylic acid groups of trisodium citrate with $\mathrm{Fe}(\mathrm{III})$ ions. $^{36,47}$

DLS analysis showed that mean hydrodynamic size distribution of bare MNGs and PEG/Ca(II)/MNGs were centered at 164 and $170 \mathrm{~nm}$, respectively. As shown in Figure 4A, no broadening of size distribution occurred, which suggests that no aggregations in bare MNGs and PEGylated MNGs occurred. Shifting the hydrodynamic size distribution from 164 to $170 \mathrm{~nm}$ is related to $\mathrm{Ca}(\mathrm{II})$ doping and PEGylation. To further confirm the success of PEGylation, the corresponding TEM and SEM images of MNGs after PEGylation were obtained. As shown in Figures 4B and C, both TEM and SEM images show a spherical hollow layer with a thickness of $\approx 5 \mathrm{~nm}$ covering the MNGs. With their combination of biocompatibility, magnetism and monodispersity, magnetic nanocarriers have potential in various applications, especially in nanobiotechnology.

\section{Cytotoxicity Study}

In order to be applied in a gene delivery experiment, the cytotoxicity of magnetic nanocarrier against $E$. coli and Hek293T cells were tested. Cytotoxicity assay was done under three incubation times. The results for $E$. coli show that cell viability and proliferation were not hindered by the magnetic nanocarrier at a wide concentration range and three incubation times of 1,2 , and 3 hours (Figure 5A). Furthermore, the results of viability of treated Hek293T cells show that after their exposing with different concentrations of 


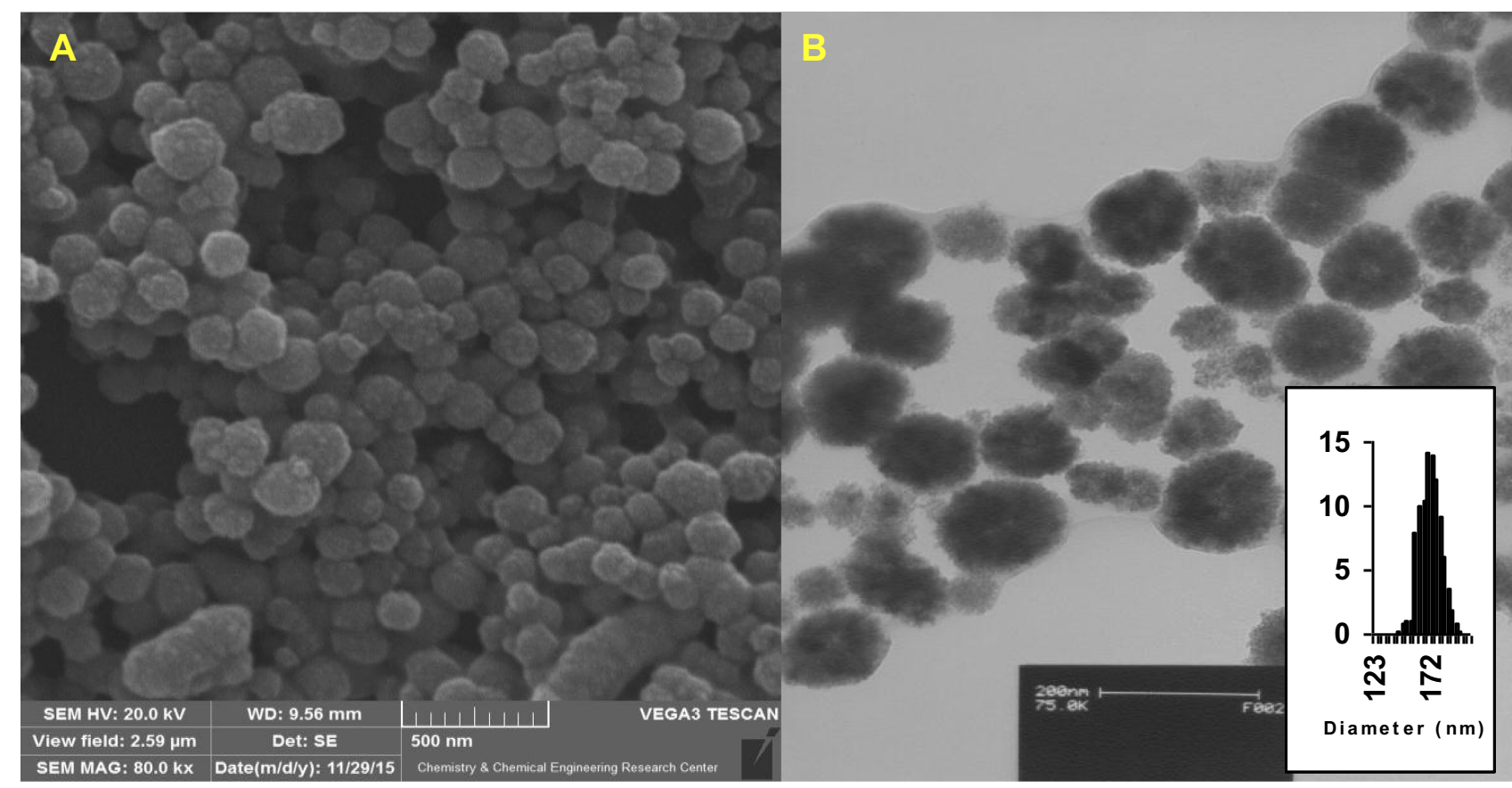

Figure 3 (A) SEM of bare MNGs. (B) TEM of bare MNGs; inset: size distribution of MNGs.

nanocarrier $(0.1,1$, and $10 \mu \mathrm{g} / \mathrm{mL})$, the nanocarrier was not toxic and the viability rates were $98 \%, 95 \%$, and $92 \%$, which are not significant. However, in 100 and $500 \mu \mathrm{g} / \mathrm{mL}$ of nanocarrier, the viability rates were significantly decreased.

\section{Delivery of PUC19 Plasmid into E. Coil Membrane}

In the optimized experimental conditions, magnetic nanocarrier was applied to the delivery of PUC19 plasmid into the E. coli membrane. A modified Sambrook protocol was applied for gene transfection. ${ }^{38}$ Different ratios of nanoparticle/plasmid were applied to obtain high transformation efficiency. The obtained results show that high ratio of nanocarrier/plasmid increased transfection efficiency. This increase continued to a toxic concentration level of nanocarrier in which the number of bacterial colonies was dropped. The transformation rate is evaluated by colony numbers counting. Transformed cells are able to live and continue their growth on antibiotic-selective medium, while the untransformed cells will die. Comparison between the transformed bacteria plates after treatment and the control group is presented in Figure 5B.

Gene delivery in bacterial cells is highly dependent on the nanocarrier concentration. High concentrations of nanocarrier are toxic. For example, in the presence of 15 and 20 $\mu \mathrm{L}$ of nanocarrier, the colony numbers decreased to $73 \pm 6.7$ and $44 \pm 3.9$, respectively. However, $10 \mu \mathrm{L}$ of nanocarrier dramatically dropped the colony numbers to $97 \pm 6.4$, which was about 3-fold more than the control group (traditional method) with a $30 \pm 2.8$ colony (Figure $5 \mathrm{~B}$ ).

We selected $10 \mu \mathrm{L}$ as the optimized concentration for transformation, as it was in this concentration that the highest colony number was seen. At higher concentrations, the colony number dropped until reaching the least number (Figure 5B).

To obtain a concentration of nanocarrier where, at this concentration, the transformation efficiency is higher, we set up a series of experiments by adding $10 \mu \mathrm{L}$ of nanocarrier in different steps of transformation.

The results presented in Figure 5C show that in group 1, in which the nanocarrier was added at the initial step of transformation, the number of colonies was significantly changed in comparison with the control group (132 \pm 9.5$)$. In group 2 (156 \pm 10 ), in which the nanocarrier was added before the heat shock, the number of colonies were more than the control group, with the highest number of colonies. In group 2, the bacteria were exposed with the nanocarrier for 30 minutes less than in group 1 . The results show that, during the 30 minutes incubation of bacteria on the ice-bath, the presence of a nanocarrier is not essential to increase the transfection efficiency. Perhaps the decreasing colony numbers are because of the potential toxicity of the nanocarrier. In group 3, addition of the nanocarrier increased the transfection rate ( $99 \pm 8.5$ ), but this was less than group 1 and 2 (see Figures $5 \mathrm{E}-\mathrm{G}$ ). This result 


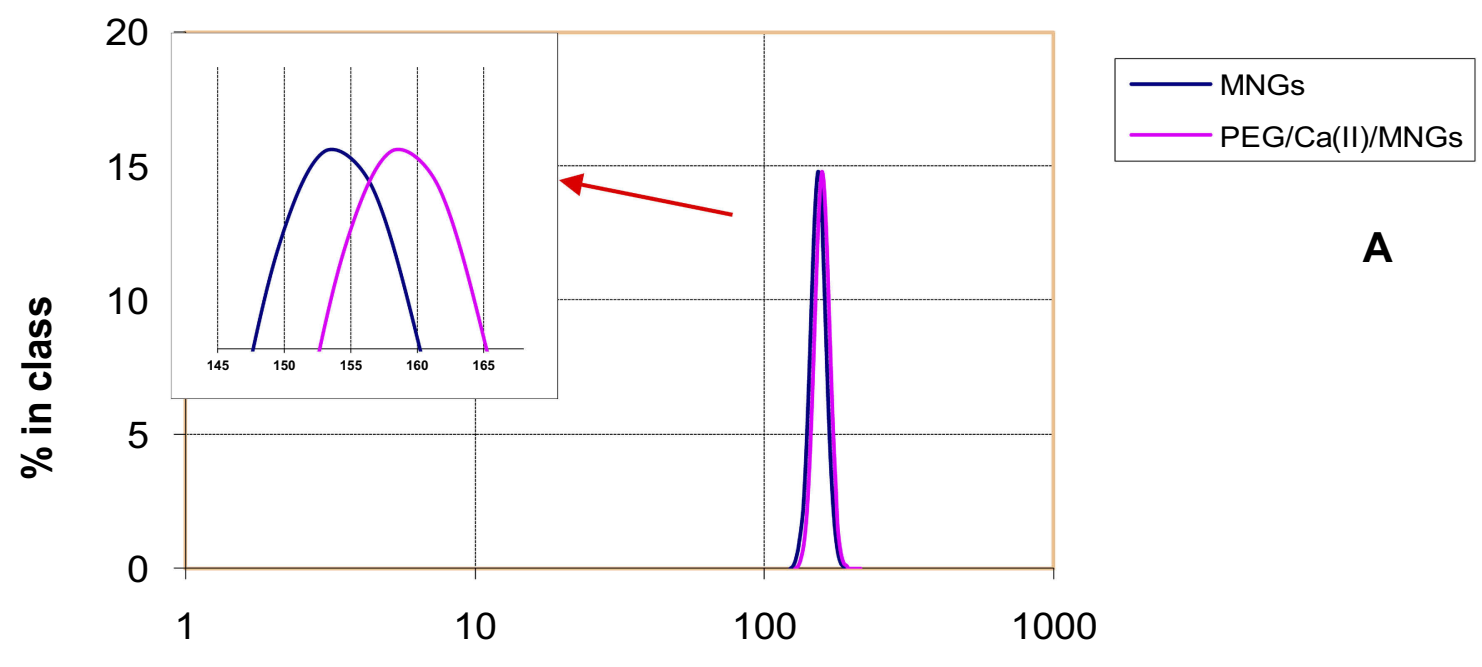

\section{Diameter (nm)}
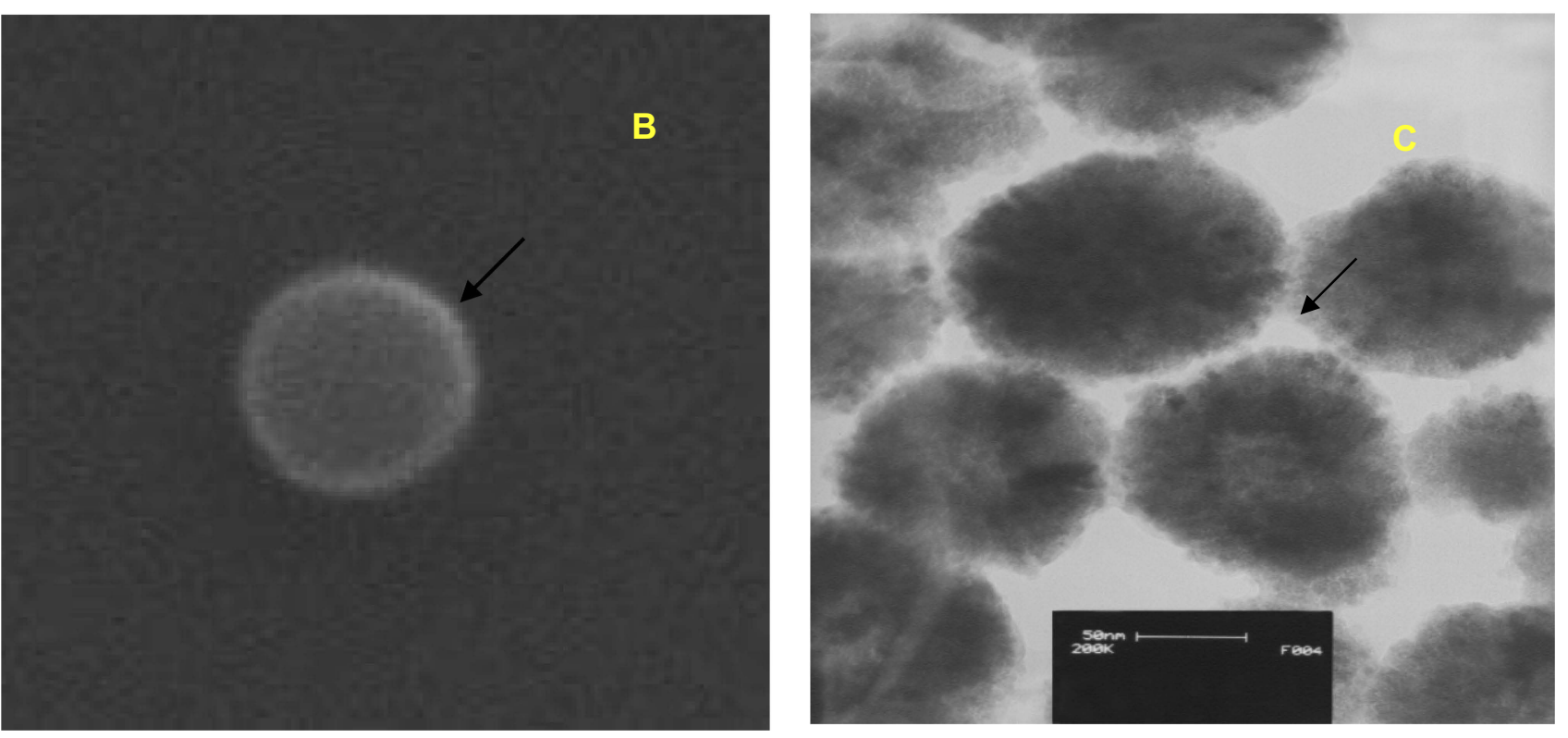

Figure 4 (A) Size distribution of bare MNGs and PEG/Ca(II)/MNGs. (B) TEM image of PEG/Ca(II)/MNGs. (C) SEM image of PEG/Ca(II)/MNGs (scale bar is 50 nm).

could be described by less exposing (30 seconds) of bacteria with the nanocarrier. Similar results were obtained for group 4 $(65 \pm 5.6)$, where the nanocarrier increased the colony numbers but it was less than groups 1,2 , and 3 . In group 4, the bacteria exposing time was 60 minutes less than other groups. In groups $5(42 \pm 3.8)$ and $6(33 \pm 2.7)$, in which the nanocarrier was added after the heat shock, the colony numbers decreased in comparison with the control group (57 \pm 5.2$)$ (Figure 5C). The effect of neutralizing media on the efficiency of transfection process was studied. In this experiment, different volumes of neutralizing media and different concentrations of nanocarrier on the transfection efficacy were tested. The groups were as follows: 1) $5 \mu \mathrm{L}$ nanocarrier neutralized with $500 \mu \mathrm{L}$ of $\mathrm{LB}$, 2) $5 \mu \mathrm{L}$ nanocarrier neutralized with $50 \mathrm{~mL}$ of $\mathrm{LB}, 3) 10 \mu \mathrm{L}$ nanocarrier neutralized with $500 \mu \mathrm{L}$ of LB, 4) $10 \mu \mathrm{L}$ nanocarrier neutralized with $5 \mathrm{~mL}$ of LB, 5) $20 \mu \mathrm{L}$ nanocarrier neutralized with $500 \mu \mathrm{L}$ of LB, (6) $20 \mu \mathrm{L}$ nanocarrier neutralized with $5 \mathrm{~mL}$ of LB, and 7) control group. As shown in Figure 5D, the best efficiency was obtained for group 1 with $(150 \pm 10)$ colonies when $5 \mu \mathrm{L}$ nanocarrier neutralized with $500 \mu \mathrm{L}$ of LB. As a result of this experiment, diluting the nanocarrier with more neutralized media decreased the toxiceffect of the nanocarrier. 

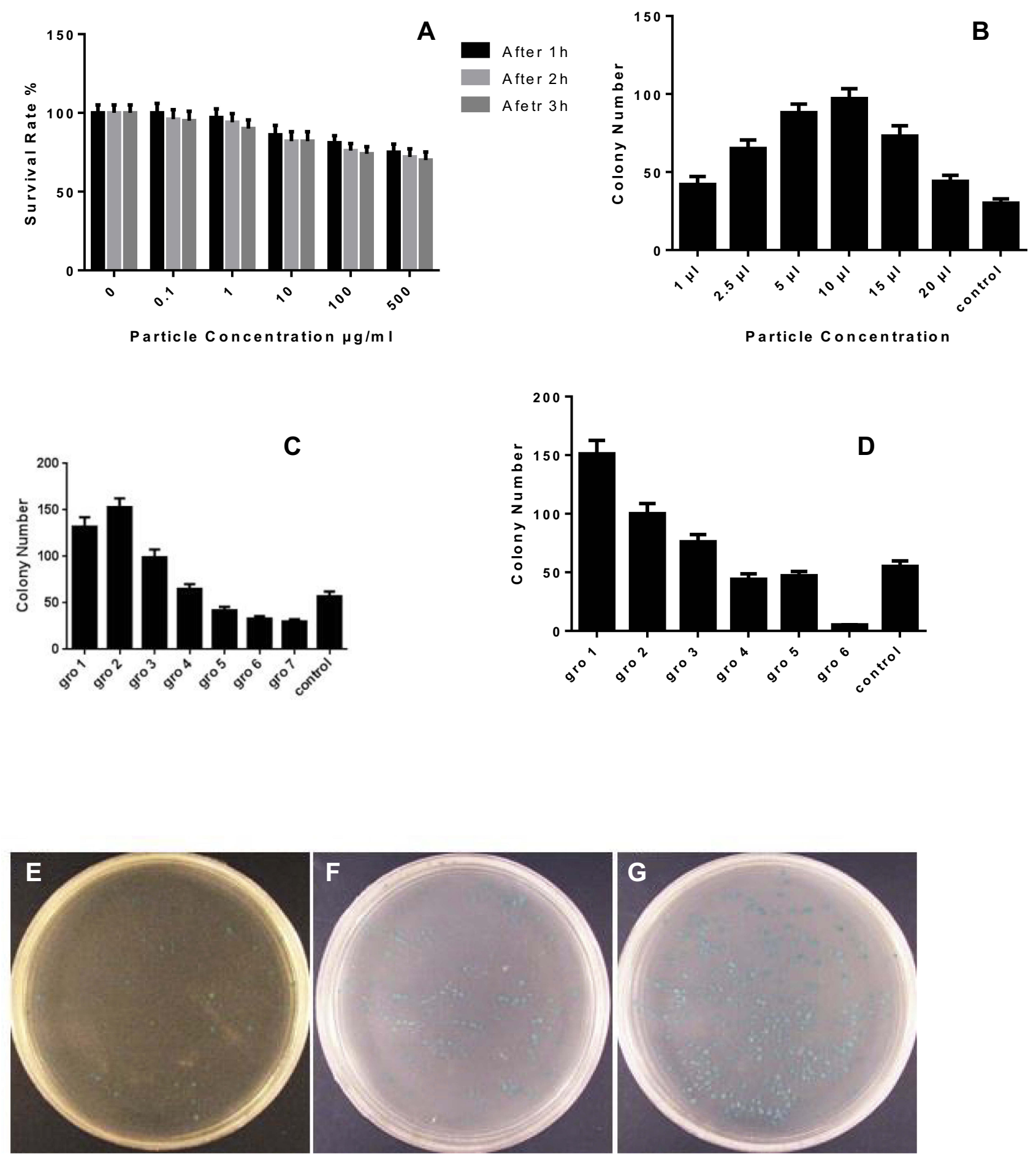

Figure 5 (A) Viability assay of $E$. coli in three incubation times. (B) Relation between nanocarrier concentration and number of colonies. (C) Relation between nanocarrier concentration variations in different gene delivery steps and colony number. (D) Effect of LB volume on the colony number. The colony number evaluation of transformed bacteria cells, (E) control, (F) group 2, (G) group I. The blue colonies show viable and transformed bacteria.

\section{Success, Quality, and Purity of Transfected Plasmid}

To examine the success, quality, and purity of transfected plasmid, the transfected plasmid was extracted from treated colonies using a commercial plasmid extraction kit. The isolated plasmid was subjected to control the endonuclease digestion. Figure 6A shows the agarose gel electrophoresis of transformed plasmid. The efficiency of the transformation process has increased dramatically by using magnetic nanograin as a gene carrier. After electrophoresis in agarose gel, the 


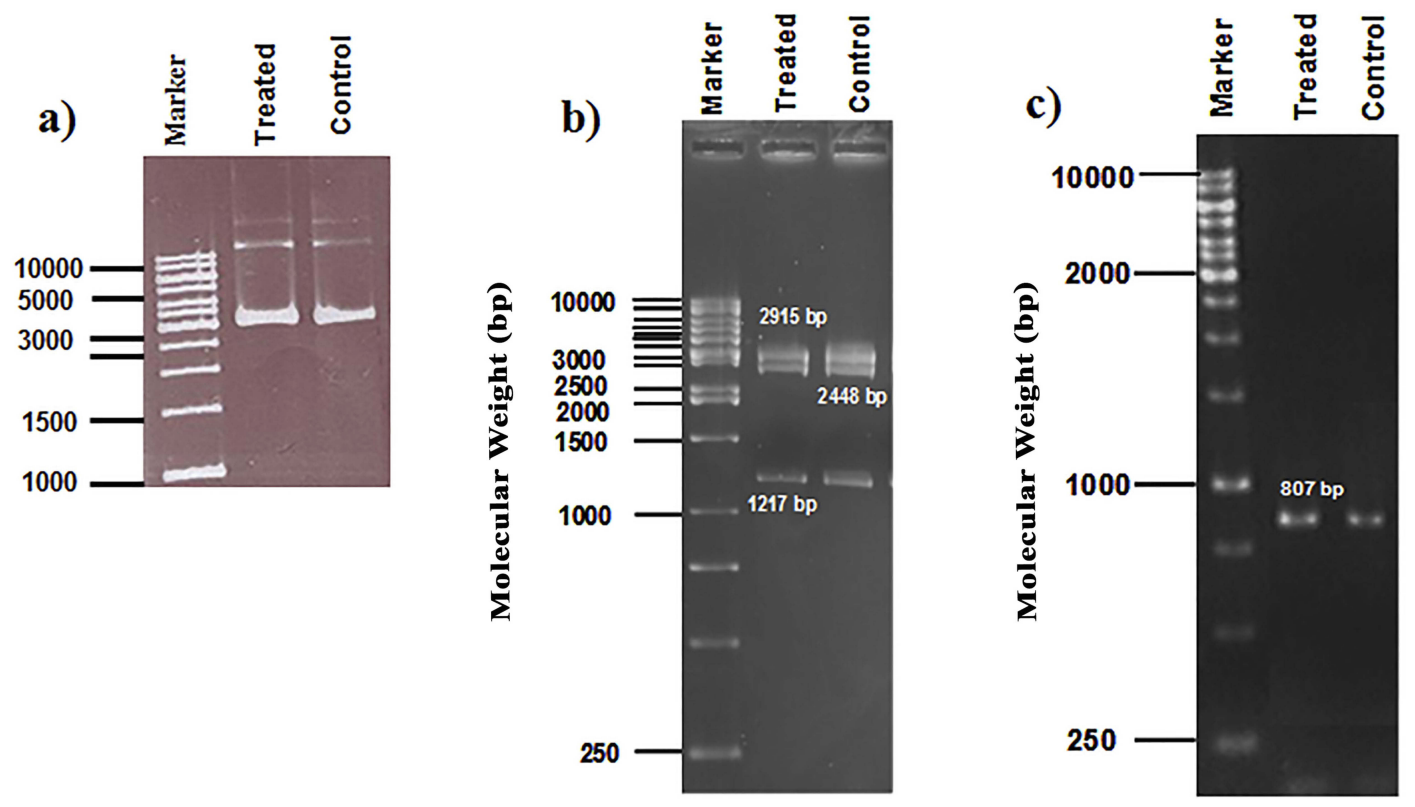

Figure 6 (A) Agarose gel electrophoresis of extracted plasmid. Lane I: molecular marker, Lane 2: treated, Lane 3: control: (B) Restriction endonuclease digestion. Lane I: molecular marker, Lane 2: enzyme digested pDNA extracted from treated-cells, Lane 3: enzyme digested pDNA extracted from control cells. (C) Agarose gel electrophoresis of NeoR gene (807 bp amplicon). Lane I: DNA molecular weight marker; Lane 2: treated sample; Lane 3: control.

digested plasmid showed a negligible fragmentation (Figure 6B). As shown in Figure 4B, the digestion was effective and no band of undigested plasmid was found. Finally, to assess the quality of transferred plasmid using magnetic nanocarrier, polymerase chain reaction (PCR) was made on the NeoR gene. Figure $6 \mathrm{C}$ shows the $807 \mathrm{bp}$ amplicon of NeoR in the treated band which is accorded with the control group and molecular weight marker.

\section{Gene Expression Analysis in HEK-293 T Cells}

The relative gene expression analysis by qPCR showed that treated cells by nanocarrier enhanced the GFP expression 1.4-fold more than the control group (Lipofectamine 2000), which shows a significant differences $(P \leq 0.05)$ (Figure $7 \mathrm{C})$. Furthermore, microscopic analysis revealed that the GFP expression rate in nanocarriers treated cells was remarkably higher than in the control group (see Figures 7A and B).

\section{Discussion}

The modified solvothermal synthesis protocol is presented in Figure 1. Briefly, three carboxylate groups of trisodium citrate create a strong coordination affinity to three valence iron ions resulting not only in citrate groups on magnetic nanocrystals (MNCs) but also preventing the nanocarrier from aggregation. ${ }^{36}$ Another role of trisodium citrate is to render the surface of the nanocarrier more biocompatible. To the best of our knowledge, citric acid is widely used in food and drug industries and has a key role in the normal metabolic process in the human body (tricarboxylic acid cycle). Ethylene glycol works as a solvent and its excess serves as a reductant. ${ }^{36}$ Sodium acetate serves as the source of alkali media. The citrate anions on the spherical surface of MNGs captured $\mathrm{Ca}^{2+}$ ions by ion exchange process and a layer of PEG was coated on the MNGs surface. $^{36}$ It is reported that PEG can reduce the nonspecific cellular uptakes. ${ }^{39}$

In this paper the cytotoxicity of the nanocarrier was tested and a non-toxic concentration of nanocarrier for $E$. coli and Hek293T cells was determined. Previous studies revealed that all nanoparticles exhibit a dose-dependent cytotoxicity, but dose-dependent toxicity of the synthesized magnetic nanocarrier is negligible. ${ }^{48}$ In addition, PEG protected the positive charge of magnetic nanocarrier and caused a proton sponge structure which protected the cell membrane damage due to abundant positive charge. This is an issue for cationic polymers which are used as non-viral vectors. ${ }^{15}$ The obtained non-toxic concentration of nanocarrier was applied for gene delivery and the results, which are presented in Figure 5, showed an increase in the gene delivery efficiency by adding nanocarrier. High plasmid transfection efficiency is a crucial factor in gene delivery. Naked plasmid cannot penetrate to 

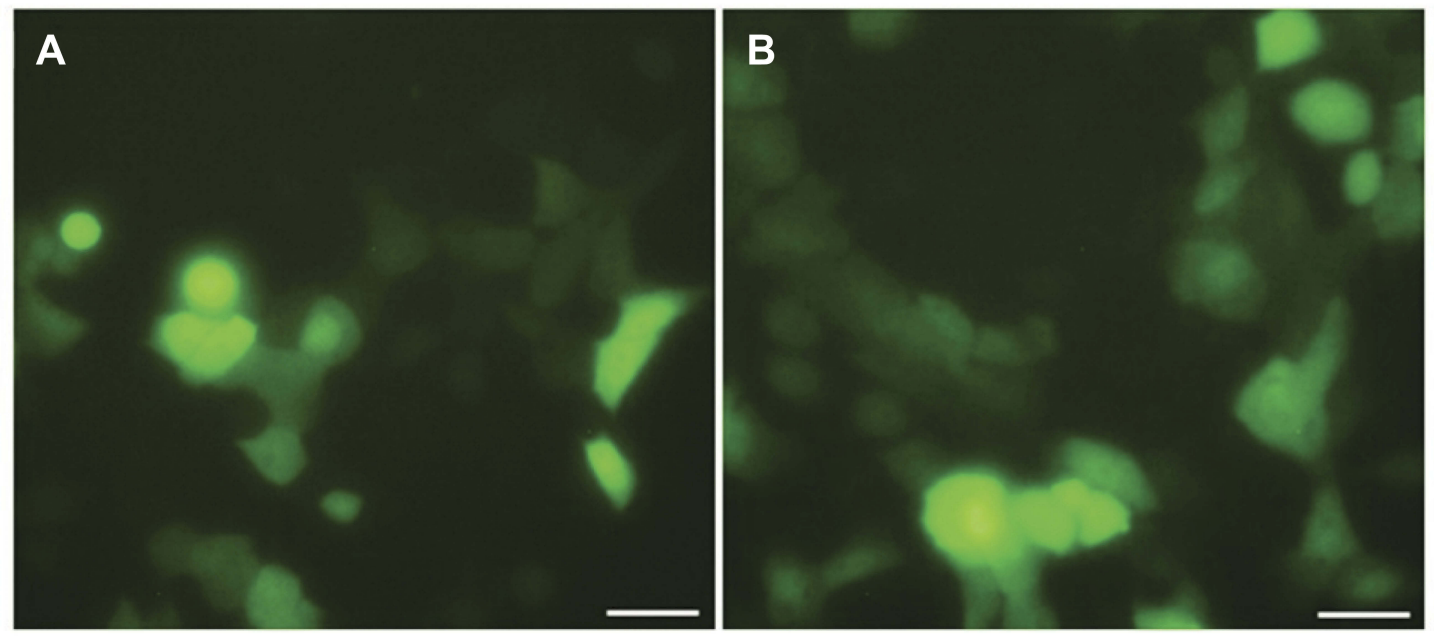

C

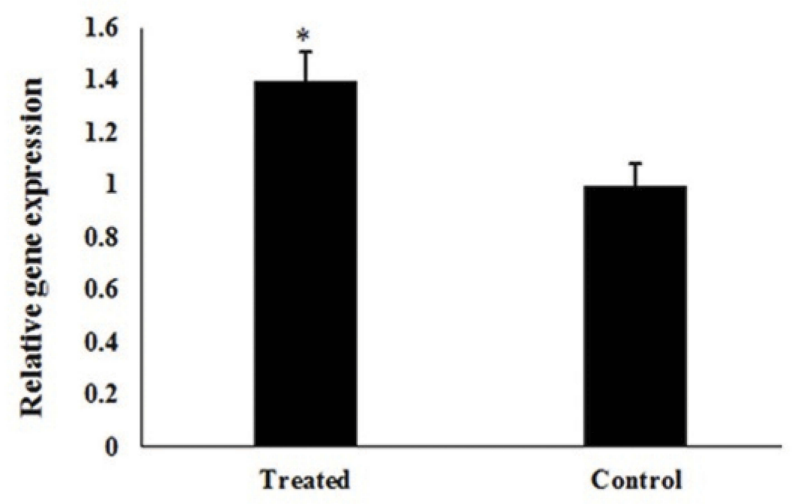

D

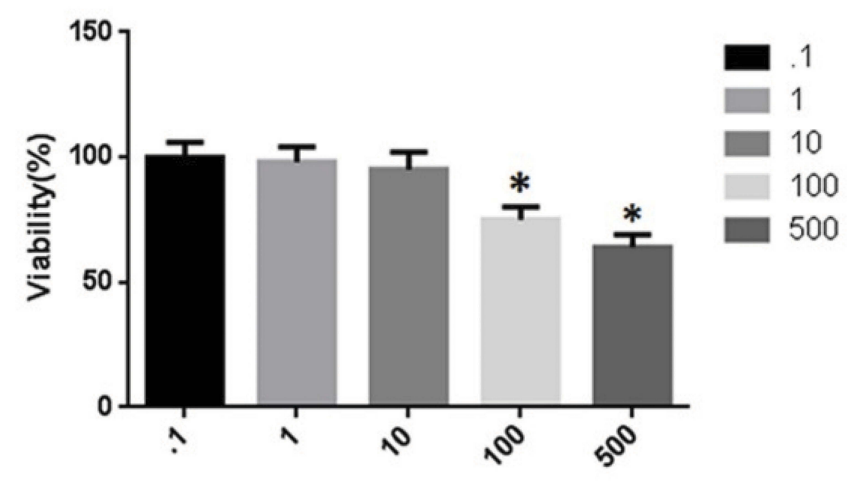

Concentration $(\mu \mathrm{g} / \mathrm{ml})$

Figure 7 Gene delivery efficiency of GFP by PEG/Ca(II)/MNGs: (A) Phase contrast fluorescence microscopy image of transfected cells in the Control group. (B) Fluorescence image of transfected GFP in cells by PEG/Ca(II)/MNGs. (C) Relative GFP expression by qPCR in treated cell by PEG/Ca(II)/MNGs and lipofectamine 2000 as a standard method (Scale bar is $20 \mu \mathrm{m}$ ). (D) Viability of exposed HEK 293T cells to PEG/Ca(II)/MNGs. All experiments were performed in triplicate.

bacteria membrane due to electrostatic repulsion between anionic bacteria membrane surface and negative charges of plasmid. Therefore, plasmid might be absorbed on the positively charged magnetic nanograin surface to pass through bacteria membrane. A plasmid (containing an antibiotic resistance gene) penetrates a bacterial cell, resulting in viability of bacteria when cultured in antibiotic-selective medium. However, untransformed cells are not able to growth in such selective medium. Results in Figure 5 revealed that the nanocarrier could be able to enhance the transformation rate.

In this work the mechanism of increasing the gene delivery rate was evaluated and the best step for addition of the nanocarrier, to obtain the best efficiency, was assessed. The data showed that addition of the nanocarrier before and after the heat shock does not have any positive effect on the transformation rate. In addition, we found that the best step for adding a nanocarrier is exactly before and during the heat shock period. Our results are a first report that introduce the best protocol for increasing the transformation rate. In some groups, the colony number was decreased. This decrease in the colony number in groups 5 and 6 could be due to the toxicity potential of the nanocarrier. Further, they could not transfer plasmids to bacterial cells and led to a drop in colony numbers. The importance of gene delivery in clinical therapy in some genetic diseases like diabetes, heart diseases, or in molecular biology labs is not hidden. However, the efficiency and adverse effects of gene carriers are the main issues. Better understanding of cell state, during a physiological process such as transformation, can reduce the toxic effects of the nanocarrier. Using this information, one can find at what stage the gene delivery process achieves less adverse effects on cells. In this work, by testing at which step we can add a nanocarrier to obtain high efficiency and lowest toxicity, we reached the optimum period and also the best concentration of the nanocarrier. 


\section{Conclusions}

In this study we have shown the utility of a gene expression response of $\mathrm{PEG} / \mathrm{Ca}(\mathrm{II})$ assembly of magnetic nanograin in both eukaryote and prokaryote systems. We confirmed the biocompatibility of nanograins in different incubation times and a wide concentration range. We have also shown a plausible mechanism for the gene expression process. The results of this study show that doping calcium ions on the nanograins dramatically increased the transfection efficiency of PUC19 plasmid onto E. coli bacteria membrane and GFP expression in HEK-293 T cells.

\section{Acknowledgements}

We gratefully acknowledge the financial support from the Iran National Science Foundation (INSF; project number 96005771) and Research Council of the Hamadan University of Medical Sciences (9703081282).

\section{Disclosure}

The authors report no conflicts of interest in this work.

\section{References}

1. Choi YS, Lee MY, David AE, Park YS. Nanoparticles for gene delivery: therapeutic and toxic effects. Mol Cell Toxicol. 2014;10:1-8. doi:10.1007/s13273-014-0001-3

2. Chen J, Jiao ZX, Lin L, et al. Polylysine-modified polyethylenimines as siRNA carriers for effective tumor treatment. Chin J Polym Sci. 2015;33:830-837. doi:10.1007/s10118-015-1632-0

3. Yadegari A, Khezri J, Esfandiari S, et al. Bottom-up synthesis of nitrogen and oxygen co-decorated carbon quantum dots with enhanced DNA plasmid expression. Colloids Surf B. 2019;184:110543. doi:10.1016/j. colsurfb.2019.110543

4. Jin S, Leach JC, Ye K. Nanoparticle-mediated gene delivery. Methods Mol Biol. 2009;544:547-557.

5. Wu Y, Wang W, Chen Y, et al. The investigation of polymer-siRNA nanoparticle for gene therapy of gastric cancer in vitro. Int J Nanomed. 2010;5:129-136.

6. Eltoukhy AA, Sahay G, Cunningham GM, Anderson DG. NiemannPick $\mathrm{C} 1$ affects the gene delivery efficacy of degradable polymeric nanoparticles. ACS Nano. 2014;8:7905-7913. doi:10.1021/nn501630h

7. Song H, Wang G, He B, et al. Cationic lipid-coated PEI/DNA polyplexes with improved efficiency and reduced cytotoxicity for gene delivery into mesenchymal stem cells. Int J Nanomed. 2012;7:4637-4648.

8. Cheng L, Li Y, Zhai X, Xu B, Cao Z, Liu W. Polycation-b-polyzwitterion copolymer grafted luminescent carbon dots as a multifunctional platform for serum-resistant gene delivery and bioimaging. ACS Appl Mater Interfaces. 2014;6:20487-20497. doi:10.1021/am506076r

9. Bardi G, Malvindi MA, Gherardini L, Costa M, Pompa PP, Cingolani R. The biocompatibility of amino functionalized $\mathrm{CdSe} /$ $\mathrm{ZnS}$ quantum-dot-doped $\mathrm{SiO}_{2}$ nanoparticles with primary neural cells and their gene carrying performance. Biomaterials. 2010;31:6555-6566. doi:10.1016/j.biomaterials.2010.04.063

10. Pantarotto D, Singh R, McCarthy D, Erhardt M, Briand JP, Prato M. Functionalized carbon nanotubes for plasmid DNA gene delivery. Angew Chem Int Ed. 2004;43:5242-5246. doi:10.1002/anie.200460437
11. Karmakar A, Bratton SM, Dervishi E, et al. Ethylenediamine functionalized-single-walled nanotube (f-SWNT)-assisted in vitro delivery of the oncogene suppressor p53 gene to breast cancer MCF-7 cells. Int J Nanomed. 2011;6:1045-1055.

12. Li K, Feng L, Shen J, et al. Patterned substrates of nano-graphene oxide mediating highly localized and efficient gene delivery. ACS Appl Mater Interfaces. 2014;6:5900-5907. doi:10.1021/am5008134

13. Zhang Y, Wang Z, Zhou W, Min G, Lang M. Cationic poly(caprolactone) surface functionalized mesoporous silica nanoparticles and their application in drug delivery. Appl Surf Sci. 2013;276:769-775. doi:10.1016/j.apsusc.2013.03.168

14. Song H, Yu M, Lu Y, et al. Plasmid DNA delivery: nanotopography matters. J Am Chem Soc. 2017;139:18247-18254. doi:10.1021/ jacs.7b08974

15. Chaudhary A, Garg S. siRNA delivery using polyelectrolyte-gold nanoassemblies in neuronal cells for BACE1 gene silencing. Mater Sci Eng C. 2017;80:18-28. doi:10.1016/j.msec.2017.05.101

16. Seferos DS, Prigodich AE, Giljohann DA, Patel PC, Mirkin CA. Polyvalent DNA nanoparticle conjugates stabilize nucleic acids. Nano Lett. 2009;9:308-311. doi:10.1021/n1802958f

17. Giljohann DA, Seferos DS, Daniel WL, Massich MD, Patel PC. Gold nanoparticles for biology and medicine. Angew Chem Int Ed. 2010;49:3280-3294. doi:10.1002/anie.200904359

18. Guo S, Huang Y, Jiang Q, et al. Enhanced gene delivery and siRNA silencing by gold nanoparticles coated with charge-reversal polyelectrolyte. ACS Nano. 2010;4:5505-5511. doi:10.1021/nn101638u

19. Cole AJ, David AE, Wang J, Galbán CJ, Hill HL, Yang VC. Polyethylene glycol modified, cross-linked starch-coated iron oxide nanoparticles for enhanced magnetic tumor targeting. Biomaterials. 2011;32(8):2183-2193. doi:10.1016/j.biomaterials.2010.11.040

20. Berry CC, Wells S, Charles S, et al. Dextran and albumin derivatised iron oxide nanoparticles: influence on fibroblasts in vitro. Biomaterials. 2003;24:4551-4557. doi:10.1016/S0142-9612(03)00237-0

21. Berry CC, Curtis ASG. Functionalisation of magnetic nanoparticles for applications in biomedicine. J Phys D Appl Phys. 2003;36:R198206. doi:10.1088/0022-3727/36/13/203

22. Bertilsson L, Liedberg B. Infrared study of thiol monolayer assemblies on gold - preparation, characterization, and functionalization of mixed monolayers. Langmuir. 1993;9:141-149. doi:10.1021/la00025a032

23. Cai D, Mataraza JM, Qin ZH, et al. Highly efficient molecular delivery into mammalian cells using carbon nanotube spearing. Nat Methods. 2005;2:449-454. doi:10.1038/nmeth761

24. Choi CJ, Dong XL, Kim BK. Microstructure and magnetic properties of Fe nanoparticles synthesized by chemical vapor condensation. Mater Trans. 2001;42:2046-2049. doi:10.2320/matertrans.42.2046

25. McBain SC, Yiu HH, Dobson J. Magnetic nanoparticles for gene and drug delivery. Int $J$ Nanomed. 2008;3(2):169-180.

26. Baoum AA, Ovcharenko D, Berkland CJ. Calcium condensed cell penetrating peptide complexes offer highly efficient, low toxicity gene silencing. Int J Pharm. 2012;427:134-142. doi:10.1016/j.jpharm.2011.08.012

27. Baoum AA, Berkland CJ. Calcium condensation of DNA complexed with cell-penetrating peptides offers efficient, noncytotoxic gene delivery. J Pharm Sci. 2011;100:1637-1642.

28. Haberland A, Knaus T, Zaitsev SV, et al. Calcium ions as efficient cofactor of polycation-mediated gene transfer. Biochim Biophys Acta. 1999;1445:21-30. doi:10.1016/S0167-4781(99)00017-2

29. Chen X, Guo P, Xie Z, Shen P. A convenient and rapid method for genetic transformation of E. coli with plasmids. Antonie Van Leeuwenhoek. 2001;80:297-300. doi:10.1023/A:1013040812987

30. Zaitsev S, Buchwalow I, Haberland A, et al. Histone H1-mediated transfection: role of calcium in the cellular uptake and intracellular fate of H1-DNA complexes. Acta Histochem. 2002;104:85-92. doi:10.1078/0065-1281-00633

31. Ziello JE, Huang Y, Jovin IS. Cellular endocytosis and gene delivery. Molecular Med. 2010;16:222-229. doi:10.2119/molmed.2009.00101 
32. Baoum A, Xie SX, Fakhari A, Berkland CJ. "Soft" calcium crosslinks enable highly efficient gene transfection using TAT peptide. Pharm Res. 2009;26:2619-2629. doi:10.1007/s11095-009-9976-1

33. Asif A, Mohsin H, Tanvir R, Rehman Y. Revisiting the mechanisms involved in calcium chloride induced bacterial transformation. Front Microbiol. 2017;8:2169. doi:10.3389/fmicb.2017.02169

34. Wu SY, Chang LT, Peng S, Tsai HC. Calcium-activated gene transfection from DNA/poly(amic acid-co-imide) complexes. Int J Nanomed. 2015;10:1637-1647.

35. Sandhu AP, Lam AM, Fenske DB, Palmer LR, Johnston M, Cullis PR. Calcium enhances the transfection potency of stabilized plasmid-lipid particles. Anal Biochem. 2005;341:156-164. doi:10.1016/j.ab.2005.02.033

36. Deng H, Li X, Peng Q, Wang X, Chen J, Li YD. Monodisperse magnetic single-crystal ferrite microspheres. Angew Chem Int Ed. 2005;44:2782. doi:10.1002/(ISSN)1521-3773

37. Phadatare MR, Khot VM, Salunkhe AB, Thorat ND, Pawar SH. Studies on polyethylene glycol coating on $\mathrm{NiFe}_{2} \mathrm{O}_{4}$ nanoparticles for biomedical applications. $J$ Magn Magn Mater. 2012;324:770-772. doi:10.1016/j.jmmm.2011.09.020

38. Sambrook J, Fritschi EF, Maniatis T. Molecular Cloning: A Laboratory Manual. New York: Cold Spring Harbor Laboratory Press; 1989.

39. Xie J, Xu C, Kohler N, Hou Y, Sun S. Controlled PEGylation of monodisperse $\mathrm{Fe} 3 \mathrm{O} 4$ nanoparticles for reduced non-specific uptake by macrophage cells. Adv Mater. 2007;19:3163-3166. doi:10.1002/ adma.200701975

40. Willis AL, Turro NJ, O'Brien S. Spectroscopic characterization of the surface of iron oxide nanocrystals. Chem Mater. 2005;17:5970. doi: $10.1021 / \mathrm{cm} 051370 \mathrm{v}$
41. Bronstein LM, Huang X, Retrum J, et al. Influence of iron oleate complex structure on iron oxide nanoparticle formation. Chem Mater. 2007; 19:3624. doi:10.1021/cm062948j

42. Yee C, Kataby G, Ulman A, et al. Self-assembled monolayers of alkanesulfonic and -phosphonic acids on amorphous iron oxide nanoparticles. Langmuir. 1999;152:7111-7115. doi:10.1021/1a990663y

43. Nan Z, Chen X, Yang Q, Wang X, Shi Z, Hou W. Structure transition from aragonite to vaterite and calcite by the assistance of SDBS. J Colloid Inter Sci. 2008;325:331-336. doi:10.1016/j.jcis.2008.05.045

44. Lin Y, Lin Y, Wang L, Ngo S, Ma Y. Renal perfusion assessment using magnetic nanoparticles with $7 \mathrm{~T}$ dynamic susceptibility contrast MRI in rats. J Magn Magn Mater. 2019;475:76-82. doi:10.1016/j. jmmm.2018.11.041

45. Salas G, Veintemillas-Verdaguer S, Morales Mdel P. Relationship between physico-chemical properties of magnetic fluids and their heating capacity. Int $J$ Hyperthermia. 2013;29(8):768-776. doi:10.3109/02656736.2013.826824

46. Farmany A, Shamsara M, Mahdavi H. Enhanced electrochemical biosensing of buprenorphine opioid drug by highly stabilized magnetic nanocrystals. Sensors Actuat B-Chem. 2017;239:279-285. doi:10.1016/j.snb.2016.08.007

47. Kim M, Chen Y, Liu Y, Peng X. High-quality $\mathrm{Fe}_{3} \mathrm{O}_{4}$ dendron-nanocrystals dispersible in both organic and aqueous solutions. Adv Mater. 2005;17:1429. doi:10.1002/adma.200401991

48. Babincova M, Sourvong P, Leszczynska D, Babinec P. Blood-specific whole-body electromagnetic hyperthermia. Med Hypotheses. 2000;55:459-460. doi:10.1054/mehy.2000.1089 


\section{Publish your work in this journal}

The International Journal of Nanomedicine is an international, peerreviewed journal focusing on the application of nanotechnology in diagnostics, therapeutics, and drug delivery systems throughout the biomedical field. This journal is indexed on PubMed Central, MedLine, CAS, SciSearch ${ }^{\mathbb{R}}$, Current Contents ${ }^{\mathbb{B}} /$ Clinical Medicine,
Journal Citation Reports/Science Edition, EMBase, Scopus and the Elsevier Bibliographic databases. The manuscript management system is completely online and includes a very quick and fair peer-review system, which is all easy to use. Visit http://www.dovepress.com/ testimonials.php to read real quotes from published authors.

Submit your manuscript here: https://www.dovepress.com/international-journal-of-nanomedicine-journal 